\title{
Continuous Enrolment: Heresies, Headaches and Heartaches
}

\author{
Lynda Yates \\ Faculty of Education \\ La Trobe University \\ Bundoora, 3086. Victoria. Australia \\ Tel: 61-3-9479-1077 \\ Fax: 61-3-9479-3070 \\ E-mail: 1.yates@latrobe.edu.au
}

The research is financed by the Department of Immigration and Citizenship, Australian Commonwealth Government. (Sponsoring information).

\begin{abstract}
In this paper I report on a research project designed to address the question of how the policy of continuous enrolment has been working in practice in the AMEP (Adult Migrant English Program), the national English language program offered to newly-arrived migrants to Australia. Managers, teachers and learners from around Australia were interviewed individually or in focus groups to ascertain their views on the policy and its management. The literature on continuous enrolment has focused almost exclusively on adult education in North America, and has generally found little positive support for the policy among teachers. The results of this study indicate that the potential benefits to students in the context of the AMEP may outweigh the considerable disruption to classes it causes. In two of the three participating centres, the students were overall very positive about starting class immediately, and many teachers also appreciated these benefits for students and were developing strategies to minimize the negative effects. Similarly, while the managers generally recognized the organizational and pedagogical headaches that the policy caused, they appreciated the flexibility it gave them to open and manage classes according to local conditions. I argue that these more sympathetic views are a product of the unique context and history of the AMEP as a nationally-supported on-arrivals program, but that positive measures are nevertheless necessary in order to address the issues caused by continuous enrolment.
\end{abstract}

Keywords: TESOL, Continuous enrolment, Open enrolment, Adult Migrant English Program, Program management, Settlement

\section{Introduction}

'Continuous enrollment' (Beder and Medina, 2001) or 'open enrolment' (Comings, Soricone and Santos, 2005) basically refers to the right for a student to enrol in a program without waiting for traditional semester dates. (Note 1) The introduction in 2000 of this policy into the Adult English Migrant Program (AMEP) in Australia means that providers to are now required offer eligible migrants a place in the program within one month of registration, a move that has led to a re-think of enrolment patterns around the country, and attracted a lot of comment by teachers. (Note 2, Note 3) The AMEP is put out to tender and delivered by a range of providers nationally, and different centres have managed continuous enrolment in different ways. However, competition between providers has meant that information on how they do this has not always been shared freely.

Anecdotal evidence has suggested that this policy is a major challenge to managers and teachers in the AMEP, and yet there is very little research to date on its benefits and/or disadvantages or on how it can be managed successfully. Most of the scholarly research to date relates to adult education settings in North America where the policy is most often discussed in terms of student drop out and turnover, that is from the perspective of 'topping up' following student attrition, or as a means of reviving flagging enrolments (Bass, 2002: 4). This literature has, for the most part, been scathing about the impact of such policies, which are seen as a pedagogical evil driven by economic necessity largely 
without benefit to either student or teacher (see, for example, Beder and Medina, 2001; Cody, Ford, and Hayward, 1998; Comings et al, 2005).

In this paper, I report on a project which investigated the views of managers, teachers and students around Australia on the policy and practice of continuous enrolment in the context of migrant education in the AMEP. I address the question of whether it is worth doing, that is, whether the benefits outweigh the disadvantages, and if so, how it can best be managed.

\section{The Literature}

As noted above, much of the research on continuous enrolment comes from the field of adult literacy in the US which has practised continuous enrolment since the1960s. In this context, there are two main arguments in its favour. First, the ability to enrol in a class without waiting for traditional entry points is argued to offer flexibility to adult students for whom employment and family responsibilities make regular class attendance difficult (Comings et al, 2005; Robinson-Geller, forthcoming; Sticht, McDonald and Erickson, 1998). An added benefit is that, if properly handled through sensitive and inclusive enrolment management, this flexibility can shake institutions out of a complacent take-it-or leave-it attitude towards student needs. This means that, in theory:

At its loftiest, enrolment management is about an institution's relationship with its students and when practised correctly should improve those relationships (Walker, 2000: 129).

A second argument for continuous enrolment, and cynics would argue the most persuasive, is economic, in that high attrition rates in adult education programs led to the need to top up classes on an ongoing basis in order to maintain the financial viability of programs (Bass, 2002). In addition, in higher education, flexibility in enrolment patterns can be used as a weapon in the war for the best students, with institutions using flexible enrolment plans to tempt students to their institutions and away from others, what Walker (2000) describes as the development of an 'ugly underbelly' (p.130).

However, a further argument in favour of continuous enrolment, and one of the most important for the AMEP, comes from migrant education and relates to the 'heartaches' referred to in the title. Silver (1986), reporting on the experiences of the English department of an international institute in the US offering continuous enrolment in English programs, argues that it is absolutely crucial to offer migrants access to English classes as soon as they arrive, that is, without having to wait for standard enrolment periods. Since classes offer learners access not only to language instruction but also a means of becoming more familiar with their new environment and engagement with new social networks, being able to start classes immediately helps them to become more independent and to combat the depression that may otherwise develop if they remain isolated in their new country.

These arguments notwithstanding, there is very little support in the educational literature for continuous enrolment as an educational practice in adult literacy because of the many, serious 'headaches' that it causes teachers, students and managers. Open enrolment in the US has entailed both continuous entry and flexible exit (Robinson-Geller, forthcoming), and also flexibility in attendance, so that classes are in a state of constant flux. Moreover, Bass (2002) argues, in many US adult basic education programs students are accepted into programs whatever their instructional level in order to fill vacant places. This means that classes not only experience frequent new arrivals and departures, but also have to accommodate a range of levels that are difficult to teach as a single group.

Writing in the US, Beder and Medina (2001) are highly critical of both open enrolment and mixed level classes and see these as the most serious issues to be confronted in adult literacy education. Such views are echoed also in NCSALL Reports \#23 and in Comings et al (2005). Similarly, Cody et al (1998), reporting on gaps and issues in the Knox County, Tennessee adult and family literacy program, also found continuous enrolment to be a serious impediment to success.

The critiques of continuous enrolment in these contexts, therefore, relate not only to the instability of the class, but also to the concomitant mixture of abilities (Comings et al, 2005; Robinson-Geller, forthcoming; Wardell, 1991) and their effects on student progress (Comings et al, 2005). Criticisms centre on the significant interruptions caused to classes as teachers bring new students up to speed, the almost inevitable disruption to classroom climate and dynamics, as well as the headache of planning class activities for a constantly changing cohort. Beder and Medina (2001) warn that such disruptions may encourage the use of traditional methodologies rather than more innovative approaches, as a constantly changing class makes it difficult to organise group or project work. As drop-outs increase, so project work and peer coaching becomes more problematic.

The stress of having to juggle this situation leads to teacher burnout (Bass, 2002; Beder and Medina, 2001) which, in turn, can lead to student disaffection and erratic attendance (Sticht et al, 1998). While teachers can make use of students who have been in the class for longer to help 'mentor' new arrivals, there is some evidence that this may sometimes be a further cause of resentment among students (Ramirez, 2005). Critiques also highlight the difficulties that the students, themselves, experience when they join a class that has been running for some time: they may find it intimidating to 
enter a class which has already covered points that they have inevitably missed out on (Cody et al, 1998). Thus the practice allowing continuous enrolment into classes seems to have little support pedagogically in the literature.

However, it should be noted that the policy of continuous enrolment into a centre may be managed at an organisational level so that it does not necessarily entail ongoing entry to already established classes: intakes can be staged so that students may enrol in a centre constantly throughout a term but not actually join a regular ongoing class until later. Beder and Medina (2001), for example, suggest the organisation of holding cohorts, that is, groups that students can join immediately until such time as the members enter a regular class. Cody et al (1998) recommend incorporating a new Learning Skills class in which new students are enrolled for up to one month before entering their regular classes, which therefore receive new enrolments only at the end of each month.

In ESL contexts, special classes can be arranged outside the regular class. A pilot program of managed enrolment in non-credit ESL in which eight week sessions were held and attendance requirements were enforced seems to have been successful both for the students and the staff in a community college in California (Ramirez, 2005). Other strategies proposed in the literature to mitigate the difficulties posed by continuous enrolment relate to good systemic organization and communications within a centre. Writing about the adult migrant context, Silver (1986), for example, argues for the careful reception, assessment and placement of new students in appropriate classes through a pre-class interview and language testing, followed-up by a system which ensures that teachers have relevant background information on students. As we shall see, similar strategies have also been used in the AMEP. These organisational measures notwithstanding, this brief review of the literature has highlighted enormous dissatisfaction with the pedagogical practice of continuous enrolment into classes.

In Australia, too, anecdotal accounts suggest that teachers find continuous arrivals into the AMEP disruptive and difficult to manage. Writing soon after the introduction of the requirement for continuous enrolment, a teacher notes the confusion and disorientation experienced by students joining an already-established class and laments the 'disjointed and disparate group' that her class became and the 'planning headache' that the policy caused (Henenberg, 2000: 7). Eight years on, we have very little current information on whether this policy is worth the disruption that it appears to bring in its wake, what stakeholders think about it and what it looks like in practice in a national migrant education program. I address these important questions in the project reported below.

\section{The Study}

The project sought to address the following research questions:

1. How is the policy of continuous enrolment managed in different centres?

2. What are the views of managers, teachers and students on continuous enrolment?

3. What strategies might assist teachers and managers to manage it successfully?

Three AMEP providers from three different states responded positively to an invitation to participate in the study. Two of the providers (A and B) were departments in larger colleges of Technical and Further Education (TAFEs), and the third I was a smaller private college dedicated to second language training. (Note 4) The views of learners, teachers and managers in the three centres were sought in focus groups and interviews arranged in each state. In each case, the groups consisted of volunteers who were approached through a liaison in the provider. In two of the three, focus groups were also arranged with students outside classes (A and C); in the third (B), the focus group occurred inside class time. The teachers were all qualified professionals with a range of experience, and their profile generally reflected that of the majority of full-time teachers in the AMEP, that is, mature, experienced and female. I met with managers individually in each centre, and conducted an additional telephone focus group with a group of managers in a remote location in one state. Additional data were also collected from a focus group of experienced managers and curriculum developers from other providers in two further states at a national AMEP conference. (Note 5)

The sample of students in the focus groups in centres A and B included learners from a range of classes, from post-beginner and intermediate (principally from levels 2 and 3 in the national curriculum CSWE, but with a few from level 1 ). (Note 6) In centre B, however, for logistical reasons the focus group took place in a single class with the teacher present at CSWE level 3 (intermediate). The focus groups were conducted primarily in English, although the more advanced students translated for their fellow students who were not able to fully express themselves in English. In one provider, centre A, this enabled lower level students to contribute their views also. A summary of the data collected is given in Figure 1:

\section{[insert Figure 1 here]}

The groups were asked for their views on continuous enrolment, whether they thought it was useful, how it is currently managed and for any alternative suggestions for the successful management of new arrivals. A guide to the questions each group was asked is given in Appendix 1. The same interviewer facilitated discussion in each case. The discussions were recorded, transcribed and analysed for themes and insights. In a second phase of the project, groups of teachers 
from one provider worked with me to develop, trial and evaluate some strategies for managing continuous enrolment appropriate to their teaching context (see Yates, 2006).

In this paper I primarily address the question of whether the policy of continuous enrolment is worth doing from the perspective of the three stakeholder groups (research question 2), but in doing so I first describe briefly how the three providers managed continuous enrolment (a partial response to research question 1; see also Yates, 2006). Research question 3 is addressed briefly here and more extensively in Yates (2006).

\section{How continuous enrolment is managed}

Of the three providers, only the smaller, private college, Centre C, enrolled students continuously into ongoing classes (see above discussion). Students normally started within a few days of their enrolment interview, even if this was very near the end of the term. Like the centre described in Silver (1986), this continuous flow was managed by a combination of a thorough initial interview and placement assessment, together with regular communications between interviewers, managers and teachers.

As is customary in every provider, students were given an initial interview at which their circumstances, goals and current proficiency level was established. This was very thorough, and the information gathered was used to place the student into a class sensitively in the most appropriate of the wide range of classes offered. A fine-grained set of descriptors was developed each term for each class, defining not only the level but also the pace at which the class was working (that is, a kind of streaming), and this facilitated appropriate placement. As discussed below, the managers and the students seemed relatively happy with this arrangement, and despite the inevitable frustrations of constant new arrivals, many of the teachers felt that they could work with it, even though communication within the centre did not always happen as planned. However, this approach seemed to rely heavily on the fact that the centre was a small and specialised in language training: there was some evidence that it was becoming more problematic as the programs within the school, and therefore the school itself, expanded.

Centres A and B both used the concept of a holding class (Beder and Medina, 2001; Cody et al, 1998) to manage enrolments after the beginning of term. In centre A, which operates in a smaller city where the students were usually refugees and often with lower levels of education, this took the form of an orientation program in which they were introduced to the local area and were able to acclimatize to learning styles and find out about settlement issues. However, in smaller, rural campuses of the same provider, this was not organizationally feasible and students were enrolled into the regular classes throughout the term. This was seen by the managers as a positive, since it allowed them to start classes with smaller student numbers than would normally be viable and therefore ensured that some language provision was possible in a location that otherwise would have been without.

In centre B, enrolment was continuous into regular classes for the first four weeks of a ten week term and then a part-time holding class for students who already had some basic English was opened after five weeks of term. This provided a general orientation to learning until the student could join a regular class the following term. Lower level students were either put into a part-time class or counselled to see if they would be happy to study in another type of venue within the same provider. Although the structural solution to the requirement for continuous enrolment was similar to that in centre A, there did seem to be some difference in stakeholder views in the two centres, as we shall see below.

\section{Is Continuous Enrolment Worth Doing?}

Given the largely negative anecdotal comment on and accounts of continuous enrolment in the literature, it feels somewhat 'heretical' to conclude that, overall, it is worth the disruption it causes. However, provided that it is properly supported and managed appropriately on a number of levels, this is what the data from this study suggest. Justification for this claim comes largely from centres $\mathrm{A}$ and $\mathrm{C}$ and the conference focus group of professionals from other states. It is supported by the positive views expressed by the students at these centres, and given guarded support from those managers and teachers who have found ways of working with it.

For students, the ability to start English study as soon as possible offered a vital avenue of escape from the heartaches they were suffering as they started in a strange new country and lost touch with everything that was familiar to them. The managers generally appreciated the flexibility it gave them in organising classes. From staffroom comment, insights from other projects (for example, Wigglesworth, 2003; Yates, in press) and from the literature (Robinson-Geller, forthcoming; Beder and Medina, 2001; Comings et al, 2005; Sticht et al, 1998; Wardell, 1991), I had expected very negative responses to continuous enrolment from the teachers in this study - a litany of headaches! However, while they certainly expressed their frustrations in dealing with the policy in practice, I was surprised by the sympathy shown to the needs of the students, so that the teachers were, if not exactly zealous converts to continuous enrolment, then at least apparently reconciled to finding ways of working that accommodated it. They were more varied in their responses than the managers, and this seemed to reflect to a certain extent the culture of the centres in which they worked and their ability as individuals to cope with change. 
The more negative views expressed by all three groups in centre B suggests that this culture of accommodation to continuous enrolment does not necessarily occur automatically in a centre. The fact that only a limited number of students, all from the same class with the teacher present, may help to explain way the students were less positive. However, views were collected from a range of teachers and managers, suggesting that disaffection with continuous enrolment may have been widespread in this provider, and perhaps this discontent may also have influenced how their students responded to questions about the policy. I saw less evidence in this centre of commitment to overt strategies that could mitigate the most serious negative consequences of the policy. In centres $\mathrm{A}$ and $\mathrm{C}$, in contrast, the judicious use of a variety of strategies helped to alleviate the most deleterious effects, and the teachers' acute awareness of the benefits to students of starting to learn English as soon as possible was probably a vital ingredient in this. That is, they found that continuous enrolment into classes was disruptive and difficult to manage, but that the evident benefit to students encouraged them to devise and put into operation strategies to mitigate these disadvantages. I expand below on the challenges and the benefits of continuous enrolment raised by the participants in the study.

\section{Critiques of continuous enrolment}

Criticism of continuous enrolment focussed mostly on the entry of students into classes that had already formed, rather than to the formation of holding classes, and it was the teachers who expressed the most reservations. These often related very closely to those found in other studies and clustered around two main themes: the problems caused managing learning in a constantly changing class and the disadvantages for the students of this environment.

The teachers in all focus groups found the interruption to classes and the almost inevitable repetition of some elements of class frustrating, although they did not agree on which level of classes were more difficult to handle in this way. They generally reported finding that the continuous arrival of newcomers to their classes made it difficult to be systematic in building on previous learning in their teaching and in managing assessment tasks for the class, because some learners would be ready for a particular assessment task and others would not. This made it difficult to plan towards final outcomes:

the teachers plans and teaches the course in terms of a ten week, a discrete ten week course with a beginning, a middle and an end, and if students are coming during that course, it's sort of disruptive and the teachers find it difficult and possibly the students don't get the best, don't get an optimal learning situation either really. (BT2) (Note 7)

Some noted that when class composition is constantly changing, class dynamics and cohesion suffers, and this was a particular problem later in the term when introductions are less appropriate as an activity and assessment is more of a priority.

Sort of second, third week, when they're still not quite a group, they haven't gelled, and then there's a new one and a new one and a new one, sometimes it makes that process very hard. (CT)

There was general agreement in all groups that continuous arrivals made assessments problematic on a number of counts. Thus, although they were many different views on when new arrivals should or should not be allowed into class, there was general agreement that they were not appropriate after about week seven of a ten week term. Even some of those who did not have to accept students after the end of the fourth week of term, still felt that accepting them within the first four weeks was disruptive for both teacher and students:

it's terribly disruptive. I asked the students that you saw in my class today, before you came in, how they felt and they were quite vocal, some of them, about the fact, what they didn't like was that, and they saw it happen last term, I'm in the middle of teaching something to them, you know, a knock on the door, a student comes in a bit of paper, check the code, excuse me everybody we'd like to welcome a new student, so they didn't like the disruption, they felt that they came in to learn and it's a limited time everyday and they objected to the fact that they were constantly disruptive for about 4 weeks with students coming in, and you have to pay attention and welcome that new student, and to make them feel they fit in an introduce them to the class make them feel welcome amongst all the students, so it takes probably 5 minutes to sort all that out and they object to that. (BT3)

The teachers also reported feeling sorry for students who had to join ongoing classes and concerned that they might suffer a loss of self esteem if they were misplaced in a class or exposed to premature assessment procedures or obliged to 'repeat' the class, or find these pressures too much on top of the settlement issues they were facing:

....quite capable student who arrived when we'd just started assessments and she only appeared for two half days and never came back again. So, too hard, too hard, she wanted a lower class and yet she was very capable and was assessed accurately and was placed accurately but she got quite spooked really, by the assessment level she was faced with. $(\mathrm{CT})$

Well you're virtually saying that if they come in mid-term, unless they're exceptional students they don't progress. You know they're going to repeat that term. 
Moreover, they noted that although some new arrivals fit in very well, others do not and, while it was useful to make use of same-language peers for this settling-in process, this type of support was not always beneficial for either learner.

A major factor in the negative views of the teachers in centre B seemed to be strong misgivings about the motives for the policy: they felt that that the imperative towards continuous enrolment was financially driven rather than of particular benefit for the student: 'As I say I think it's driven by external forces which are not educationally sound forces'. (BTF) As another teacher put it 'educationally, there is nothing worthwhile about continuous enrolment'. (BT5)

The learners in centre $\mathrm{B}$ were also less positive than those in the other centres, and reported finding the constant interruptions disruptive and the need to mentor newcomers distracting:

My opinion, I think that here it is first time I study here, after four months I arrive in Australia, and I start to study in Certificate Three and I think its normal for me, but that the problem when nearly the end of the week a new student come in. You know that they start one page for me, that slows the continuity. Yeah, disturbed. (BS1)

All the time. We have this problem because when they come the teacher should stop before, to give the new ones ((another male student voice begins to speak over)), to repeat and learn the same thing.

In centre A, too, the learners spoke of the length of the challenge of adjusting to the class they joined, and their feelings of inadequacy and de-motivation if they perceived their classmates to be much more advanced (although some also found this motivating) or they had to stay longer in the same class than their classmates. They also worried about falling behind with assessment procedures and reported that feeling they had missed out on material already been covered sometimes caused frustrations:

I want to say one things, when I joined the class the first time, I didn't feel good because they was better than me. And like she said, everyone talk, talk, talk, and me, like I had a headache because I can't understand any more. And I was like, when I can be like them? And like I was really upset. (AS1)

Like the teachers, they regretted the disruption to the sequencing of lessons and the repetition of content that new arrivals in class caused to others, particularly if they were at a lower level of proficiency:

if the people the English is good and then the [[level]] yeah, it's okay. It suit me and I like it. But if the level it's like, they know nothing about English, so they like make the teacher come back, back a bit and that's I don't like it ... (AS1).

Some also disliked the time spent on the strategies used by the teachers to minimize these disruptions, such as introductions and being asked to mentor new students - although others liked this opportunity to be 'the expert'.

Managers noted that the policy of continuous enrolment meant constant changes in class number, nature and size, and therefore in staffing requirements; a constant need for childcare places; and unpredictable influxes of students. All this entailed a close monitoring of attendance, class sizes and staffing, and thus additional paperwork.

The managers in centre B, like the teachers, were largely critical of the policy and raised the issue of the tension between financial constraints and the most appropriate service to students:

.....and in terms of our budgets and our money and our finances, we need to have continuous enrolment but practical realities of the people who are coming and need to enrol is not always a possibility or the best choice for them as learners. (BM2)

They felt that in the particular student profile in their centre, more advanced learners who were ambitious in their study goals, found continuous enrolment more disruptive. However, there was not general agreement on this issue in Centres $\mathrm{A}$ and $\mathrm{C}$.

\section{Benefits of continuous enrolment}

Despite these very real concerns, the students in centres A and C were very eloquent in support of being able to start English classes as soon after their arrival as possible. They described their heartaches as newly arrived migrants - often from traumatic refugee situations - and the importance of their classes in combating the extreme homesickness and isolation they felt arriving in a completely new country on the other side of the world, echoing those reported in Silver (1986) in the US. The students felt that coming to class not only offered a start on learning or improving their English and embracing their new life ahead in Australia, but also an alternative to sitting at home besieged by unpleasant memories of the past or remembering what they have lost. Their accounts of homesickness and loneliness were often very moving and persuasive:

For me this was very good because when I arrive here, in the time I was waiting for the visa I can study, I was at home. I didn't do anything, just cry and cry. So when I remember to start in the half term, the second level, so they [[talk]] me just one day, because when I came to class and I saw people from everywhere. And the teacher was very friendly, I feel so happy to get opportunity to ((voice helps out, says 'start')) you know to start English, to be with all the people in the same case of me and so I no(t) alone ... (CS). 
But if he wait for a long time, maybe he can, or and that's not good. .... the moment you can arrive, you can join quickly, because, if you stay at home, you can not learn from anybody. Because you just remain at home, sleeping, doing nothing. (AS2)

Such accounts were not only advanced by humanitarian refugees from Africa who had often suffered considerable trauma, but also by people for whom the whole migration process was more straightforward, such as Europeans joining spouses.

Most students interviewed in centres $\mathrm{A}$ and $\mathrm{C}$, had felt welcomed by the class they were joining, even if the experience had also been daunting. Because they, themselves, had once been in the same position, most were also tolerant and appreciated the opportunities that new arrivals brought for practising and recycling what has already been taught, and the efforts their teachers made to make them feel welcome. In centre C, in particular, the very sensitive placement of students within classes that were every finely graded for level and learning pace allowed newcomers not only to be incorporated into the class, but also to be seen as a positive force:

There are two characteristics that are important, that make the fact that new students are coming is not something that could be thought of as a disadvantage. The two things that we share are that we are migrants, so we, the old ones, understand the new ones and also our level of English. The person who is coming to the class has almost our same level, so he is or she is going to talk to us and we can talk to him easily, because we are going to understand, because we have the same level. Perhaps if we in the class were people with different levels of English, it could be difficult, but because of this issue I think it's easier. (CS)

'hey asking to sit with a person who help people to do....The idea is fantastic. Good. Because always for the new arrival we want them to adjust themselves to the new city, new [[country]] XX something like that. But it is fantastic. (CS)

The teachers in centres $\mathrm{A}$ and $\mathrm{C}$ also recognised these benefits for students and also saw some positive impacts on the class of continuous new arrivals: they reported sometimes welcoming the opportunity to recycle teaching and learning in a variety of contexts, and that some new arrivals had a very positive influence on the class, making it more lively or more hard-working. Like their managers (see below), they also recognized the economic benefits to their centre and they saw the danger that students, and therefore their livelihood, might go to another centre if their own could not accommodate them. Finally, as one teacher mentioned to a chorus of agreement, patterns of attendance among adult learners, especially those simultaneously settling in a new country, tend to be erratic anyway, so that fluctuating attendance tends to be a fact of life in this educational context. As one teacher joked:

I think we have continuous enrolment because they come at half past nine, ten o'clock, half past ten [[laughter]], eleven, half past eleven. That's continuous enrolment. And lots of absences as well so ... (NC).

It was evident from both the teacher and the manager focus groups, that attitudes to managing continuous enrolment within a class were related to a certain extent to the attitude (seen by managers in some centres as personality) of the teacher. Compare, for example, the teacher who appears to thrive on change and sees it as a challenge:

I don't change my lessons at all. I just welcome them into the classroom and I tend to just absorb them in. And I don't let it worry too much, because I think I'm the sort of person that thinks, I just have to cope with what comes to me and I find a way of coping. (NC)

with the teacher who finds it disrupts her sense of how learning should be sequenced:

you don't do the third conditional at the beginning of a course for certain reasons, for example, you do the first conditional (this is a silly example), before you do the third conditional, because it is harder, but if someone walks in and they are faced straight away with the third conditional, that's not a particularly good way. Educationally I don't think it [continuous enrolment] works. (BT9)

As might be expected, the managers in all groups appreciated the economic advantages in accepting students on an ongoing basis, despite the headaches caused by the need to accommodate a continuous stream of new arrivals. Continuous enrolment helped to ensure the financial viability of classes, even when commencement numbers were low, because of the possibility of new arrivals. As noted above, this was particularly useful in rural areas where there was a smaller pool of potential students to draw on, and it often meant the difference between whether or not a class could run at all. Smaller centres also appreciated this ability, and managers generally felt the necessity to enrol students immediately in order to keep up with competitors, who might be able to offer a place if they could not:

as an organization in competition with another organization, you need to be very careful if you're going to say 'sorry, we're not going to take you [[this week]] ((another voice- 'that's right!)[...] At our centre, I'm just too afraid to knock anyone back because, I mean, we need as many students as possible. (NC)

Moreover, many managers were also ex-teachers and, like their teachers, they genuinely sympathized with a student's needs to start a program straight away: 
But I think you're dealing with real people, real people who are coming to you, wanting help. Are you going to turn them away? I don't think so.

$(\mathrm{NC})$

\section{Summary and discussion}

Many of the criticisms of continuous enrolment expressed in the study mirror those found in the adult education settings investigated in previous studies, including:

- incorporating into the class a student who is not familiar with the work already covered;

- keeping a stable working atmosphere in a class that is constantly changing;

- managing changing personalities and needs in the class;

- managing the balance between recycling material and tackling new areas;

- managing assessment;

- monitoring the progress of individual students.

Other issues related more specifically to the context of the AMEP, and the particular administrative requirements of the program:

- predicting what level classes may be running;

- placing students in the right class level;

- dealing with attendance/absence;

- managing exits from as well as entry to classes;

- finding child care;

- completing paperwork for attendance, deferrals and progress.

However, the strength of feeling expressed by many learners that starting their English classes helps to break their isolation, and the understanding and sympathy for their situation shown by many of the teachers and managers interviewed suggests that it may be possible to overcome or at least mitigate the pain of some of these difficulties.

It is interesting to speculate on why views expressed in this study are not as universally negative as those evident in previous studies conducted in adult education in the US.

First, in the context of the AMEP, there is a focus on beginnings rather than endings, that is, continuous enrolment focuses on providing for migrants as they arrive rather than making up student drop outs, as it does in adult education in the US. This allows for a much more positive view of the policy as a proactive move to cater for learner needs as they arrive to settle in a new environment, as well as an economic measure that potentially improves the viability of classes.

Moreover, the AMEP is a national program which has been running in various forms for over 50 years and draws on a highly professionalized workforce with a very strong history of empathy with their students (Martin, 1999). This long tradition of focussing on new arrivals has fostered a deep commitment to and understanding of the needs of migrants, and so teachers are perhaps more prepared for and motivated to seek solutions to the difficulties caused by continuous enrolment.

A key factor in AMEP teachers' ability to seek and develop these solutions may be their level of professionalization. Teachers in the program are all qualified TESOL professionals, many with considerable years of service in the AMEP and a sound expertise in a range of teaching strategies. They are thus better equipped to deal with the challenges of continuous enrolment than less qualified or experienced teachers. Beder and Medina (2001), for example, in their study of 20 Adult Literacy classes in eight states of the US, found little evidence that teachers were implementing concerted strategies for dealing with continuous enrolment. Rather, they reported classes in which bored students struggled with traditional teaching approaches and in which they were joined by other students on a weekly or daily basis, often without introductions or overt attempts towards classroom socialization. The classes described by Bass (2002) had similar difficulties.

Strong teacher preparation and continued professional development, it seems, is vital if teachers are to cope with the demands of varied and changing classes (Robinson-Geller, forthcoming; Beder, Tomkins, Medina, Riccioni and Deng, 2006; Bass, 2002).

It is interesting, then, that the teachers in Centre B, who were no less qualified than those in other centres, were, however, less positive. While the managers attributed this to the profile of their students (intermediate) and their more ambitious study goals, several of the students interviewed in Centre $\mathrm{C}$ also had a similar profile. The interruptions that so disturbed the intermediate students from Centre B (see quotes above from students BS1 and BS2), did not have a similar effect on a student as the same level in centre C (quote beginning "hey asking to sit with a person who help people to do'). While in a study of this kind it is not possible to explore these differences fully, it may be that the 
relative homogeneity of the group, made possible through the fine grading of classes in centre $\mathrm{C}$, mitigated the negative effects of new arrivals. However, not all centres are able to do this at all levels.

Indeed, the way in which the centre managed the policy does not seem to explain the more negative attitudes of students in Centre B, since both Centres A and B operated a holding class system so that students did not arrive continuously into established classes. Rather, the fact that teachers and managers in this centre were also more sceptical of the benefits of continuous enrolment for students at this level suggests that perhaps centre culture may be an important factor. Teachers in Centre B seemed more disturbed than the teachers in the other centres by disruptions to the sequencing of teaching and assessment, and it may be that they had more difficulty in adjusting to changing circumstances. For example, the curriculum used in the program is competency-based rather than grammatically organized, and yet one teacher illustrated the sequencing problems she had with an example from syntax (not teaching the third conditional before the first - see quote above which starts 'you don't do the third conditional).

Overall, therefore, while there seems to be sufficient evidence to suggest that it is worth finding ways to allow newly arrived migrants to start their classes as soon as possible, this view is clearly not shared by all. Although centres and teachers around Australia have developed a wide range of strategies to address issues caused by continuous enrolment, expertise in these is not necessarily shared across centres. Many of these strategies were documented in a second phase of this project. While there is no space to describe them in detail here, a summary is provided in Appendix 2, and a more extensive and contextualised version with sample activities may be found in the free downloadable resource, Yates (2006).

\section{Concluding Remarks}

Although the findings from a qualitative study of the kind reported here can only be indicative, they do provide some important insights into the goals and management of continuous enrolment in the AMEP in Australia, and thus offer insights that may be useful to other sectors and contexts. They highlight the fact that, alongside the financial drivers for continuous enrolment, there are strong humanitarian motivations and very real benefits for new arrivals. They also reinforce the conclusion of Silver (1986) that:

Open enrolment need not necessarily breed chaos, but it does require careful and thorough management.' (Silver, 1986: 1)

While I would not want in any way to minimise the chaos that results if it is not properly handled, this study has illustrated the value of finding educationally defensible ways of successfully managing enrolments so that adult migrants can have immediate access to language programs. The stakes are high for them, and it makes sense for language programs to capitalise on the strength of their desire to make a successful and positive start in their new home.

In this endeavour, however, professional development support is clearly needed if teachers are to have the skills to deal with and maintain positive attitudes towards the constant change they are experiencing in their classes. They are in the front line of the day-to-day practice of continuous enrolment, and while this study suggests that many are finding ways of coping, it is vital that they have the resources and professional development to make it work and ward off the teacher burn-out that could be just around the corner.

\section{References}

Bass, M. L. (2002). Influences on teaching and learning in adult literacy classrooms. Unpublished EdD thesis, Rutgers State University of New Jersey, NJ.

Beder, H., Tomkins, J., Medina, P., Riccioni, R. \& Deng, W. (2006). Learners' Engagement in Adult Literacy Education. A NCSALL Research Brief. Boston MA: NCSALL (National Center for the Study of Adult Learning and Literacy). [Online] Available: http://ncsall.gse.harvard.edu (July 7, 2007).

Beder, H, and Medina, P. (2001). Classroom Dynamics in Adult Literacy Education. Boston MA: NCSALL (National Center for the Study of Adult Learning and Literacy. [Online] Available: http://ncsall.gse.harvard.edu (August 6, 2005).

Cody, J., Ford, J. \& Hayward, K. (1998). A Story of Improvement. Focus on Basics: Connecting research \& practice, 2(C). [Online] Available: http://www.ncsall.net/?id=393 (September 9, 2005).

Comings, J. P., Soricone, L. \& Santos, M. (2005). An Evidence-based Adult Education Program Model Appropriate for Research. NCSALL Occasional Paper. Boston: National Center for the Study of Adult Learning and Literacy (NCSALL). [Online] Available: http://www.ncsall.net (September 9, 2005).

Henenberg, S. (2000). Ticking the box of competency. In A. Burns \& H. de Silva Joyce (Eds.), Teachers' voices. 4 : staying learner-centred in a competency-based curriculum (pp. 72-78). Sydney: National Centre for English Language Teaching and Research (NCELTR).

Martin, S. (1999) New life, new language: The history of the Adult Migrant English Program, Sydney: National Centre for English Language Teaching and Research. 
National Center for the Study of Adult Learning and Literacy (NCSALL). The First Five Years, National Center for the Study of Adult Learning and Literacy, 1996-2001. (2002, Oct.) NCSALL Reports \#23. [Online] Available: http://www.ncsall.net/index.php?id=29 (September 10, 2005).

National ELT Accreditation Scheme (NEAS). (2006). AMEP Manual, Standards and Criteria for Accreditation within the Adult Migrant English Program. Australia: NEAS. [Online] Available: http://www.neasaustralia.com/pg/pdf/AMEP\%20Manual.pdf (September 19, 2007).

Ramirez. (2005). Managed enrolment: A process- Not a product. [Online] Available: http://www.miracosta.edu/Instruction/CommunityEducation/ESL/managedenrolment.htm (July 17, 2007).

Robinson-Geller, P. (forthcoming). Individualized Group Instruction: A Reality of Adult Basic Education. In J. P. Comings, B. Garner \& C. Smith (Eds.), Review of Adult Learning and Literacy: Connecting Research, Policy and Practice (pp. 137-173). Mahwah, New Jersey: Lawrence Erlbaum.

Silver, M. (1986). Open enrolment: The professional management of chaos. Paper presented at the Teachers of English to Speakers of Other Languages Annual Convention, Anaheim, CA.

Sticht, T. G., McDonald, B. A. \& Erickson, P. R. (1998). Passports to Paradise: The Struggle To Teach and To Learn on the Margins of Adult Education. San Diego, CA: San Diego Consortium for Workforce Education and Lifelong Learning and Applied Behavioral and Cognitive Sciences.

Walker, B. (2000). Enrolment management for the 21st century: Institutional goals, accountability, and fiscal responsibility. Journal of College Student Development, 41(1), 129-130.

Wardell, D. (1991). Designing and Maintaining an ESL program for intermediate adults in an Open-Enrolment program. TESL Reporter, 24(4), 66-69.

Wigglesworth, G. (2003). The kaleidoscope of adult second language learning: learner, teacher and researcher perspective. Sydney: National Centre for English Language Teaching and Research (NCELTR).

Yates. (2006). Working with continuous enrolment. Teaching strategies-6. Sydney: AMEP Research Centre. Retrieved May 5, 2008, from: http://www.ameprc.mq.edu.au/docs/fact_sheets/06TeachingStrategies.pdf.

Yates, L. (in press). Extending TESOL teacher repertoires: Research and evidence-based professional development, Sydney: NCELTR.

\section{Appendix 1: Sample focus group questions}

Focus Group questions for Managers

How do you assign students to a class in your centre?

Describe the process and how long it takes a student to be assigned a class.

When are students permitted to join the class?

How do you make this decision?

What restrictions are there?

What is the attitude of teachers to the current policy?

What strategies do they use to accommodate new students once the class has started?

How successful are these?

Are you in favour of the policy of continuous enrolment? Why/why not? Explain any proposed alternatives. Do you think this policy affects different centres in different ways? How/why?

Focus group questions for teachers

How often do you get new students in your current class?

How do they fit in?

Do you find that you have to help them catch up?

How do you do this?

Do you use other students?

What do they think about this?

Would these answers vary for classes at different levels or for different types of students?

What do you do to help the new students settle in and catch up? Give details.

Tell me about the effect these arrivals have on the class? 
Are these effects sometimes positive?

What strategies does the management use to manage continuous enrolment?

Can you suggest any others that program managers use to manage continuous enrolment?

Do you think that students can start at times which are not near the beginning of the term?

What are the advantages?

What are the disadvantages?

Focus Group questions for students

How long did you have to wait before you started in your class?

When did you want to start?

Did you start in your class at the beginning of a term?

If not, how did you fit into the rest of the class?

How did you feel?

Did you feel that you had missed a lot of what the other students knew?

How often do you get new students in your current class?

How do they fit in?

Do you find that you have to help them catch up?

How do you do this?

Do you enjoy doing this?

What can the teacher do to help the new students settle in and catch up?

Do you think that it is a good thing that students can start at times which are not near the beginning of the term?

What are the advantages?

What are the disadvantages?

Appendix 2: Some strategies for working with continuous enrolment

Strategies at centre level

Special 'holding' or' new arrivals' classes

Sensitive placement of new arrivals

- in a class just under their current level

- with a buddy of a similar/ higher proficiency

- with same language background peers in the class

- according to skills, motivations, level of education etc.

\section{Finely graded classes}

\section{Small number of on-arrival classes}

Staged intakes at restricted times, for example:

- only on 1 day per week, only every $2^{\text {nd }}$ week etc.

- not when there is assessment

- not near end of term (for example, not in the last two weeks)

- not after 5 wks (new arrivals go to a holding class)

\section{Short learning modules which}

\section{Careful monitoring of new arrivals}

\section{Information and counselling for students}

- on when they can start

- on what continuous enrolment is and why we have it

- that they should organize and see to urgent settlement issues before they start

- on most suitable class 


\section{Handbook of relevant information}

Special information sessions for new arrivals

A buddy system in the centre or in their class

\section{Strategies to support teachers}

\section{Good communications with and within centres}

\section{Professional development sessions on:}

- Sharing strategies and techniques for managing continuous enrolment systematically.

- How to cope with discontinuity in learning:

- discrete topics each class

- getting students to work in teams

- how to recycle materials/ structures without boring continuing students

- how to revisit learning outcomes in creative ways which build on but do not depend on previous classes

- Ideas for bonding activities which can foster a supportive learning environment

- welcoming and introducing activities

- blank world map,

- 'Find someone who..'

- Activities to help class bond and maintain cohesion

- bingo

- range of other activities (see below)

- How to manage assessment within continuous enrolment

$\circ$ use of the independent learning centre

- use of an extra teacher one afternoon a week

- use of breaks for assessment

- How to use tutors/volunteers more effectively to

- manage disparate groups

- cope with orientation needs of new arrivals

- revisit areas of the curriculum covered

- Systems for keeping good records and spares of materials used

- Strategies and systems for using students as buddies and mentors

- Use of bilingual support

\section{Notes}

Note 1. While 'enrolment' is the normal spelling in British and Australian English, 'enrollment' is more common in North America, although some authors use both. As the context of this study is Australia, the former has been used throughout except in direct quotations from sources which use the alternative spelling.

Note 2. The AMEP is funded by the Commonwealth Government and offers between 510 and 910 hours (according to individual circumstances) of free instruction in English throughout Australia to all eligible migrants arriving without functional English.

Note 3. This one month time frame is specified in contracts with the relevant Commonwealth Department and extended to 3 months if a child care place is required. It is monitored by the National ELT Accreditation Scheme (NEAS) Standards and Criteria, Section D, 10.1.b.

Note 4. A TAFE is similar to a community college in North America.

Note 5. The two further states are Queensland and Victoria.

Note 6. This is a competency-based curriculum, the Certificates of Spoken and Written English.

Note 7. Extracts from the data will be names according to the participant and centre from which they were collected, that is, A,B,C, student, teacher or manager $(\mathrm{S}, \mathrm{T}, \mathrm{M})$ and with a participant number where this was discernible from 
the transcript. Thus BT2 is an extract from Teacher number 2 at Centre B. Extracts from the focus groups held at the conference are labelled NC. Individual participants were not identified in these data.

\begin{tabular}{|l|l|}
\hline Centre A & $\begin{array}{l}1 \text { teacher focus group, 1 face-to face manager interview, 1 telephone manager focus } \\
\text { group, 1 student focus group }\end{array}$ \\
\hline Centre B & $\begin{array}{l}1 \text { teacher focus group, 1 individual teacher interview, 1 face-to face manager focus } \\
\text { group, a student focus group in class time }\end{array}$ \\
\hline Centre C & 1 teacher focus group, 1 face-to face manager interview, 2 student focus groups \\
\hline National conference & Focus group of managers and senior teachers/curriculum coordinators \\
\hline
\end{tabular}

Figure 1. Summary of data collection 